\title{
La Jocoseria y otras colecciones de entremeses barrocos: la configuración de un género editorial"
}

\author{
Guillermo GÓMEZ SÁNCHEZ-FERRER \\ Universidad Complutense de Madrid - Instituto del Teatro de Madrid \\ guillermo.gomez@filol.ucm.es
}

\section{RESUMEN}

Se propone en el presente trabajo estudiar la Jocoseria benaventina en relación con las otras colecciones de piezas breves del siglo XVII como género editorial propio del Barroco. Su análisis se realizará, por tanto, en función de la configuración editorial fijada por los impresos aparecidos en los años cuarenta.

Nuestra intención es entrar en las peculiaridades, bibliográficas y editoriales, de la Jocoseria a la luz de su contexto librario para llegar a una mejor comprensión de la principal edición de las obras de Quiñones de Benavente. Para ello se atiende a las características materiales de la edición, la naturaleza de los textos recopilados o el entorno geográfico en el que se imprimen y se venden; aspectos todos ellos que determinan la recepción del lector / comprador de este tipo de libros. Para su estudio, finalmente, se contará con las aproximaciones metodológicas asociadas a la Sociología de la Edición Literaria, la Historia de la Cultura Escrita o la Bibliografía Material.

Palabras clave: Jocoseria, Luis Quiñones de Benavente, entremeses, imprenta.

\begin{abstract}
I intend to study in this article Luis Quiñones de Benavente's Jocoseria compared with other collections of short pieces written in the $17^{\text {th }}$ century, considering they all belong to the same baroque genre. Therefore, I will analyze them according to the configuration of the genre in the printed editions that appeared around the forties.

I will consider the bibliographical special features of Jocoseria regarding its printing context in order to achieve a better explanation of the nature of this edition. I will consider, as well, the material aspects of the book, the literary characteristics of the pieces collected there and the geographical surroundings where the book is printed and sold as they all influence the
\end{abstract}

* El presente estudio forma parte de la tesis doctoral Del corral al papel. Estudio de impresores españoles de teatro en el siglo XVII, financiada por el Ministerio de Educación, Cultura y Deporte (FPU AP2009-0295) e inscrita en la Universidad Complutense de Madrid bajo la dirección de los Dres. Javier Huerta Calvo y Abraham Madroñal Durán. Vaya desde aquí nuestro agradecimiento a los dos por su atención y sus constantes sugerencias. 
reception of the reader and / or buyer. In the interest of such an analysis, I will assume the methodological approaches of Sociology of Literary Edition, History of Written Culture and Physical Bibliography.

Keywords: Jocoseria, Luis Quiñones de Benavente, entremeses, printing.

Si la literatura española ha conocido durante el siglo XVII lo que hoy llamaríamos un boom editorial, ese fue, sin duda alguna, el que vivió el teatro. Gracias al éxito inicial de las Partes de comedias (continuado posteriormente con su difusión en sueltas y desglosadas), las formas dramáticas se hicieron un hueco bien notable durante el Barroco en los hogares de lectores de clases sociales muy dispares. Con todo, a pesar de que la presencia del teatro entre los impresos literarios -de por sí minoritarios- del mil seiscientos ocupa un lugar modesto en comparación con otras formas editoriales ${ }^{1}$, el fenómeno ha merecido la atención de numerosos estudiosos que -con Edward Wilson y Don W. Cruickshank a la cabeza- han analizado la transmisión de nuestras obras dramáticas. No resulta extraño si tenemos en cuenta que el teatro áureo se convirtió en "una empresa comercial bien organizada, a la que muchos dramaturgos habrían de suministrar una gran cantidad de textos"2 para los corrales y -nos permitimos añadir-para las prensas.

Las comedias conocieron pronto un éxito librario sin precedentes amparadas en las populares partes. El teatro breve, por el contrario, aunque nacido y criado a la sombra de los volúmenes mayores de teatro, ha seguido un camino particular más centrado en la realización escénica y en la transmisión manuscrita que en la perduración del texto compuesto en letras de molde. En este sentido, J. C. González Maya ha destacado recientemente que una de las peculiaridades de este tipo de textos (tan apreciados sobre las tablas) es que, "a pesar de su éxito, nunca o casi nunca se publicaron de manera simultánea a su estreno en las tablas, al igual que las come-

\footnotetext{
${ }^{1}$ A pesar de las limitaciones que ofrecen las fichas bibliográficas de J. Simón Díaz (sobre todo en lo que a las comedias sueltas se refiere), punto de partida del estudio de J. L. Aguirre (1987), los datos a los que llega en su artículo siguen presentando cierto interés para la materia que aquí nos ocupa. Según su análisis, tan solo un $14,17 \%$ del total de obras literarias impresas en el siglo XVII son textos dramáticos, muy por debajo de los demás géneros literarios -la poesía, la historia, la novela y, por supuesto, la prosa religiosa o hagiográfica-. Si además tenemos en cuenta que los impresos literarios fueron más minoritarios que los libros de devoción, moral, filosofía, ciencia o historia en las prensas del Siglo de Oro, como anota K. Whinnom (1980), entenderemos mejor ese boom literario del teatro que se refleja en las prensas españolas. Con todo, aunque datos como los anteriores sean reflejo de una realidad editorial, invitamos al lector a tomar siempre con cautela cualquier dato bibliométrico, dada la cantidad de ediciones que se han perdido con el paso de los siglos.

${ }^{2}$ G. Vega García-Luengos (2003), p. 1289.
} 
dias. Los autores de las compañías los incorporaban a su repertorio y solo años después de su paso por la escena los entregaban a la imprenta" ${ }^{3}$.

Si desde bien pronto en el siglo encontramos recopilaciones de obras extensas, de manera constante desde las tempranas Seis comedias de Lope de Vega (Lisboa, Pedro Craesbeck, 1603), no fue hasta los años cuarenta del siglo cuando "[1] os mercaderes de libros e impresores [...] se dieron cuenta de que estas piezas cortas se habían convertido en objeto de lectura, tal y como había sucedido con las comedias" ${ }^{4}$. Con todo, ya en los primeros impresos teatrales del siglo podemos encontrar libros en los que se atiende ocasionalmente al espectáculo teatral en tanto que fiesta y no simplemente como texto dramático ${ }^{5}$. En consecuencia, en algunos de esos tanteos editoriales tempranos del siglo de Calderón se añaden piezas breves a las colecciones de teatro, acaso como alternativa a los que salieron en pliegos sueltos o recogidos en obras de carácter eminentemente narrativo. En el caso de los libros dramáticos, fue la edición de la Primera parte de comedias de Lope de Vega (Zaragoza, Angelo Tavanno, 1604 y sucesivas reediciones tempranas), que incluye loas y entremeses (estos solo a partir de la edición de Valencia, Gaspar Leget, 1605) a modo de experimento comercial, la primera y más importante tentativa editorial en lo que se refiere a las colecciones de teatro (breve y extenso) del XVII.

La iniciativa tuvo cierta continuidad en impresos tan peculiares como las Ocho comedias y ocho entremeses nuevos nunca representados de Miguel de Cervantes (Madrid, viuda de Alonso Martín, 1615), también ellos impresos en cuarto, compuestos en Lectura, con los entremeses agrupados al final... Aunque el mejor ejemplo de la aceptación de dicho modelo son las reediciones de las obras del Fénix: de tal modo a partir de la edición vallisoletana de la Primera parte (Juan Bostillo, 1609), compuesta siguiendo la de Valencia ${ }^{6}$, la Tercera parte de las comedias de Lope de Vega y otros auctores que se imprime en Sevilla con un falso pie de imprenta $^{7}$ o las partes séptima (Madrid, viuda de Alonso Martín, 1617 y Barcelona, Sebastián de Cormellas, 1617) y octava (Madrid, viuda de Alonso Martín, 1617 y

${ }^{3}$ J. C. González Maya (2012), p. 18.

${ }^{4}$ C. C. García Valdés (2012), p. 15-16. Para un primer acercamiento a las colecciones de entremeses del siglo XVII y su desarrollo desde 1640 hasta más allá del primer tercio del siglo XVIII, véase además J. C. González Maya (2012), pp. 21-30.

${ }^{5}$ No puede quedar duda sobre dicha intención si tenemos en cuenta que algunos de los primeros impresos teatrales del siglo se presentan al lector con el fin de "ofrecer los textos como sustitutos del espectáculo para aquellos que no pueden asistir. [...] Otra prueba de este afán conectivo es el recordatorio que bastantes piezas llevan en los índices de los tomos y en los encabezamientos respectivos de las condiciones de representación, en especial cuando se trata de fiestas celebradas en Palacio ante sus Majestades, funcionando como una suerte de reclamo comercial". G. Vega García-Luengos (2010), p. 61.

${ }^{6}$ Ver M. G. Profeti (1995).

${ }^{7}$ Ver J. Moll (1974). 
Barcelona, Sebastián de Cormellas, 1617) de sus comedias, donde se puede apreciar la importancia que en los primeros años del siglo llegaron a cobrar las obras cortas en los impresos dramáticos.

En esta misma línea, algunos años más tarde, rozando las fechas de la primera edición de la Jocoseria, volvemos a encontrar unas Fiestas del Santísimo Sacramento (Zaragoza, Pedro Vergés, 1644) donde se recogen las obras de Lope de Vega -pues como suyas se imprimen todas las piezas del volumen a pesar de que sabemos por otros testimonios que, al menos varios de los entremeses aquí incluidos, pertenecen a Quiñones de Benavente- divididas en doce fiestas, compuesta cada una por una loa, un entremés y un auto. La estructura espectacular del impreso está aún más clara en este caso en el que José Ortiz de Villena, compilador del volumen, le ofrece al "letor amigo [...] este libro a quien intitulo Fiestas del Santísimo Sacramento, repartidas en doce autos sacramentales, cada uno con su loa y su entremés para que se hallen hechas las fiestas en los lugares como se representaron en esta corte"

Es por entonces también, en los años cuarenta del siglo, cuando los impresores empiezan a dejar constancia de manera decidida del teatro breve escrito en el XVII. Tras algunos escarceos con otras disposiciones en la impresión de teatro durante los primeros años de la centuria, que incluyen las piececillas de los intermedios con sus correspondientes comedias o autos, los primeros volúmenes íntegramente compuestos por obritas breves aparecerán en esta década, a menudo influenciados (directa o indirectamente) por el éxito de la Jocoseria. La estrategia editorial adoptada para las piezas de Quiñones de Benavente entronca con la rápida difusión del nuevo modelo editorial y forma parte del repentino florecimiento de varias de las colecciones de piezas breves de la época. En estos años:

Los editores empezaban a vislumbrar la rentabilidad de los tomos de entremeses sin comedias, y sabían también que los más interesantes eran sin duda de aquel autor que "más suele escribirlos", porque "hay pocos que lo hagan" (Loa con que empezó Roque de Figueroa). ${ }^{9}$

A partir de 1640 las colecciones de entremeses, loas, bailes, jácaras y mojigangas, como las (re)bautizó Emilio Cotarelo, adquieren entidad por derecho propio y se configuran en torno a unas características genéricas que se mantendrán constantes a lo largo del siglo ${ }^{10}$. En un espacio temporal muy corto confluyen la aparición

\footnotetext{
${ }^{8}$ L. F. Vega Carpio (1644), fol. 3v.

${ }^{9}$ I. Arellano, J. M. Escudero y A. Madroñal, en L. Quiñones de Benavente (2001), p. 44.

${ }^{10}$ En las siguientes páginas centraremos nuestra atención principalmente en la Jocoseria benaventina. Remitimos al lector interesado en un análisis de las características propias de las colecciones de teatro, en conjunto, a los trabajos de M. L. Lobato (1990), I. López Martín (2012) y J. C. González Maya (2012).
} 
de la Flor de sainetes (Madrid, Catalina del Barrio y Angulo, 1640) de Francisco Navarrete y Ribera, la primera recopilación impresa de teatro breve de un único autor $^{11}$, con otros volúmenes colectáneos donde se recogen casi exclusivamente textos breves. Probablemente la idea de llevar a las prensas un manojo de obritas cortas de modo exento estaba en el aire, pues también Quiñones de Benavente había iniciado con toda seguridad la confección de su Jocoseria por entonces ${ }^{12}$. En el mismo año ve la luz por primera vez en Zaragoza un pequeño volumen que se presenta con todos los aspectos que definirán las colecciones de teatro breve popularizadas poco más tarde (en formato octavo, de algo más de 250 páginas, compuesta en Atanasia, a menudo sin preliminares...) y que agrupa veintidós entremeses de muy diversos ingenios. Se trata de los Entremeses nuevos de Pedro Lanaja Lamarca (Zaragoza, 1640), recopilación que reedita las piezas aparecidas ya en la Segunda parte de las comedias del maestro Tirso de Molina (Madrid, 1635) ${ }^{13}$ con la intención de ofrecérselos al público de manera independiente, como si se tratase de una folla de entremeses en forma de libro ${ }^{14}$. Bien pronto le salieron acólitos a esos primeros Entemeses: así los Donaires del gusto (Madrid, Juan de Valdés, 1642) ${ }^{15}$, los Entremeses nuevos de diversos autores para honesta recreación (Alcalá de Hena-

${ }^{11} \mathrm{Si}$ no consideramos el antecedente de los Tres entremeses famosos a modo de comedia de entretenimiento (Baeza, Pedro de la Cuesta, 1634) de Pedro Ordóñez de Ceballos, cuya configuración material dista mucho de la que será característica de las colecciones de entremeses tal y como se asientan en las prensas a partir de 1640, es la Flor de sainetes la primera recopilación de teatro breve de un único autor. No es, sin embargo, una colección solo de teatro breve, pues "[p]or el poco volumen deste libro -dice Navarrete- me pareció henchirle destas dos novelas que se siguen, puesto que son de trabajo mío, y tan mío, que en sus intentos no he hallado a quien imitar" (2001), p. 180.

${ }^{12}$ Ver I. Arellano, J. M. Escudero y A. Madroñal, en L. Quiñones de Benavente (2001), pp. 42-48. El proceso de gestación de la Jocoseria se puede leer asimismo, con mayor detalle, en A. Madroñal (1994).

${ }^{13}$ A propósito de las ediciones tempranas de las piezas de Quiñones de Benavente y otros entremesistas coetáneos, téngase en cuenta que "parece también razonable pensar que el acicate para publicar su libro estuviera en la aparición unos años antes, en 1635, de la controvertida Segunda parte de comedias del maestro Tirso de Molina (Madrid, 1635), que incluye doce entremeses [...]. El éxito de esta iniciativa debió de ser grande, pues solo cinco años después aparece Entremeses nuevos de diversos autores (Zaragoza, Pedro Lanaja, 1640)". I. Arellano, J. M. Escudero y A. Madroñal, en L. Quiñones de Benavente (2001), pp. 43-44.

${ }^{14}$ Véanse los trabajos de J. Huerta Calvo dedicados al teatro breve áureo para la concepción de la folla de entremeses como "una modalidad de espectáculo [y no como un género dramático diferente], que podía agrupar un conjunto de piezas cortas representadas una tras otra en bulliciosa y frenética sucesión, sin la comedia" (2001), p. 80.

${ }^{15}$ En la actualidad no se conoce más que un ejemplar, en la Biblioteca Nacional de Lisboa, con signatura: RES. 757 P, ejemplar falto de la portada pero analizado por extenso por $\mathrm{H}$. Bergman (1970). Los datos de la edición son recuperables a partir de las licencias preliminares. 
res, Francisco Ropero, 1643) o el Ramillete gracioso (Valencia, 1643), cuyo raro contenido enfatiza Hannah Bergman ${ }^{16}$ destacando la clara predominancia de las piezas de Quiñones de Benavente.

Los impresores de estos años recurren al teatro breve como objeto mercantil (inserto entre otras obras dramáticas o de manera independiente) para ofrecer nuevos productos que se adaptasen al gusto de los lectores ${ }^{17}$. Debió de ser entonces cuando Quiñones, viejo y enfermo a juzgar por las palabras de Manuel Antonio de Vargas al frente de la Jocoseria ${ }^{18}$, vio la oportunidad perfecta para ofrecer a los interesados por el teatro breve su producción en un único volumen. Así, el libro en que se recogían sus mejores obras se convirtió, a la vez, en culminación de los impresos de los últimos cinco años y en modelo a seguir para otros autores y editores. No ha sido pocas veces encarecida -con razón- la importancia y la singularidad de la Jocoseria en el panorama del teatro breve español ${ }^{19}$. Los estudiosos que más energía han derrochado con el "Lope de Vega del género chico" ${ }^{20}$ se han esforzado por explicar los textos del autor "más perfecto del género entremesil" ${ }^{21}$ y han dedicado parte de su atención a analizar desde una perspectiva literaria y estructural la configuración de las ediciones en que se encuentra su obra ${ }^{22}$ pero sin entrar en algunos aspectos materiales que -como se intenta mostrar en estas páginas- podrían explicar en parte la singularidad editorial de la mayor colección del ingenio toledano.

\footnotetext{
${ }^{16}$ H. Bergman (1970).

${ }^{17}$ Téngase en cuenta que en el siglo XVII, con el auge de las formas dramáticas impresas, la lectura de teatro debía de ser más frecuente de lo que podamos imaginar a priori, "como si los textos dramáticos hubieran adquirido un estatuto de recepción híbrido entre la vista y el oído de los teatros y la lectura reflexiva de los aposentos". G. Vega García-Luengos (2003), p. 1309. Esta recepción lectora se refleja también, en parte, en las bibliotecas privadas estudiadas por J. M. Díez Borque (2010), pp. 81-89.

${ }^{18}$ Ver I. Arellano, J. M. Escudero y A. Madroñal, en L. Quiñones de Benavente (2001), p. 28.

${ }^{19}$ Se puede ver muy claramente la buena consideración en que ha tenido la crítica siempre a la Jocoseria, en detrimento de otras muestras del "teatro menor" áureo, desde finales del siglo XIX. Evidencia de ello son los estudios y ediciones de C. Rosell (1872), E. Cotarelo (1911), pp. LXXIV-LXXVIII, H. Bergman (1965), pp. 261-275 e I. Arellano, J. M. Escudero y A. Madroñal, en L. Quiñones de Benavente (2001), pp. 42-48, entre otros.

${ }^{20}$ H. Bergman (1965), p. 9.

${ }^{21}$ C. Rosell (1872), p. 3.

${ }^{22}$ Puede encontrarse una descripción de la Jocoseria y de otros impresos que en la época llevaban piezas de Quiñones en H. Bergman (1965), pp. 61-75 y 261-274, C. Andrès (1991), pp. 53-57, e I. Arellano, J. M. Escudero y A. Madroñal en L. Quiñones de Benavente (2001), pp. 42-80.
} 
La recopilación preparada por Manuel Antonio de Vargas ${ }^{23}$ para las prensas, la primera edición de la obra titulada Jocoseria: burlas veras o reprehensión moral y festiva de los desórdenes públicos, vino al mundo de la mano de Francisco García Arroyo en Madrid, en octubre de 1645, convirtiéndose con ello en la primera colección exclusivamente de teatro breve con unidad autorial. La recopilación hecha por Vargas, amigo del poeta y conocedor de los textos originales del toledano ${ }^{24}$, debió de tener una buena acogida en el mundo librario de entonces, como lo demuestran sus dos reediciones: Juan Antolín de Lago, Valladolid, 1653 y Francisco de Cays, Barcelona, 1654. Del mismo modo que les ocurriría a otros autores de la época, el auge de las piezas del toledano en los tablados tuvo una fuerza extraordinaria y precedió en varios años a su éxito impreso. Es -quizá- por la importancia que sus entremeses llegaron a alcanzar en la vida teatral del momento por lo que la crítica ha atendido más a los aspectos escénicos del entremés benaventino que a la configuración editorial de la recopilación de Vargas.

En todo caso, la colección responde en buena medida a las características de ese nuevo producto editorial que despertó el interés de los consumidores de teatro y sigue, por tanto, la estela de lo hecho en otras ediciones anteriores de teatro breve para ofrecer al público lector de la villa madrileña "doce entremeses representados y veinte y cuatro cantados" en un volumen compuesto por más de 32 pliegos, lo que hace que sea esta la colección de teatro breve más extensa de la época ${ }^{25}$. El libro de García / López vendría a enmarcarse dentro de esa nueva manera de editar el teatro breve, poniendo a disposición de los lectores un manojillo de las mejores piezas -ya que no las más recientes- de su autor ${ }^{26}$, a un precio muy asequible (mucho menor,

${ }^{23}$ Aunque no sea más que un detalle circunstancial, no deja de ser interesante el error de cierto librero a la hora de encuadernar uno de los volúmenes de la Jocoseria. En el ejemplar R/16261 de la Biblioteca Nacional de España parece celebrarse (acaso por mero despiste) más el acierto de Vargas que la genialidad de Benavente, pues se puede leer entintado en el lomo: "VARGAS | Burlas | Veras | Entremeses | [y] Varias | Loas".

${ }^{24} \mathrm{La}$ amistad que unía a Benavente con Vargas parece más que probable a la luz del texto de la dedicatoria a don Mario Mastrillo Beltrán de la Jocoseria, en la que el editor no duda -sea como artificio retórico o no- en hablar por boca del dramaturgo, y de las noticias que da sobre la enfermedad del poeta en el "Prólogo al lector". I. Arellano, J. M. Escudero y A. Madroñal, en L. Quiñones de Benavente (2001), pp. 46-47.

${ }^{25}$ Cuando Cayetano Rosell se decide a reimprimir, casi a plana y renglón, la Jocoseria benaventina a finales del siglo XIX, no duda en excusar la falta de un índice de representantes por "[e]l temor de que resultara por demás abultado e incómodo este volumen". C. Rosell (1872), p. 11. La extensión, sin embargo, no parece muy diferente a la de otros impresos en octavo de la época, empezando por el Enchiridion o El libro de los secretos de los que se tratará más adelante.

${ }^{26}$ Todas las piezas de la Jocoseria fueron escritas probablemente entre 1627 y 1639 (ver I. Arellano, J. M. Escudero y A. Madroñal, en L. Quiñones de Benavente, 2001, p. 47). Tampoco parece que estas obritas hubiesen sido puestas en escena recientemente, a juzgar por el 
al menos, que el de las omnipresentes partes de comedias). Asimismo, su situación en un punto de inflexión en la historia de la edición de las colecciones de teatro breve (justo antes de un vacío editorial del género de varios años en el mercado del libro castellano) y la calidad estética de los textos contenidos hacen que la Jocoseria ocupe una posición destacada dentro del conjunto de libros de entremeses.

El volumen, además, no es tanto una "recopilación de obras [...] a cargo del librero-editor [...] a partir de copias de actores"27 como "un conjunto artístico dispuesto según los cánones estéticos de la época -un mosaico de pedacitos escogidos por su variedad superficial, ordenados con una simetría sutil, fundidos en unidad artística por la liga de una consistente filosofía moral-"28. Es precisamente la supuesta moralidad (o no) de las piezas uno de los detalles en que más se han detenido los investigadores ${ }^{29}$. En este sentido, se ha destacado que "Benavente opera con criterios artísticos y morales en la disposición de su libro"30 y no parece fuera de lugar preguntarnos si la condición de clérigo que profesaba desde 1590 tuvo algo que ver en la selección y autocensura que se aprecia en sus obras impresas ni resulta del todo inverosímil pensar en la influencia del propio Vargas, uno de esos "poetas que componían comedias de asuntos de la Sagrada Escritura"31, a la hora de preparar los textos. En todo caso, no se ha considerado hasta ahora la posibilidad de que la mención en el título de la Jocoseria no se deba tanto a la moralidad del contenido (de la que no dudamos) como al intento de abrirse un hueco en ciertos ámbitos comerciales librescos con dicha mención ${ }^{32}$.

nombre de los autores que las representaron que se declaran en el propio impreso (ver $\mathrm{H}$. Bergman, 1965, pp. 275-364). Quizá sea por ello, en parte, por lo que Vargas insiste en el "Prólogo al lector" en que una de las causas de la edición es "que me deba su dueño el poner en la memoria de todos lo que su modestia tenía sentenciado al olvido". L. Quiñones de Benavente (2001), p. 112.

${ }^{27}$ M. L. Lobato (1990), p. 291.

${ }^{28}$ H. Bergman (1965), p. 71.

29 Antes que H. Bergman, Eugenio Asensio no dudaba en señalar que todas las piezas de la Jocoseria "[p]oseen notas comunes: brillantez y esmero literario, elegancia moral, estilización de lo cómico no por vías naturalistas sino gracias al simbolismo, propensión a la mascarada y aun a la arlequinada" (1971), p. 131, aunque José Manuel Blecua crea, más bien, que "no faltan en sus entremeses algunos atisbos curiosos de filosofía moral, como en el entremés de La paga del mundo. Sin embargo, esto es excepcional y no corriente" (1956), p. 11.

${ }^{30}$ I. Arellano, J. M. Escudero y A. Madroñal, en L. Quiñones de Benavente (2001), p. 48.

31 C. A. de la Barrera y Leirado (1860), p. 417.

${ }^{32}$ En este mismo sentido se puede argumentar, además, que se relega la alusión a las piezas que conforman el libro (entremeses, loas y jácaras) al subtítulo del mismo. Aunque no es esta la única colección de teatro breve en que se destierra la mención genérica del título (de los dos títulos, en este caso) del volumen y se desplaza al subtítulo, lo habitual (salvo en casos extremos como el de la miscelánea Coronas del Parnaso y platos de las musas de Alonso Jerónimo de Salas Barbadillo) era que desde el mismo título apareciese el tipo de 
Parece claro que la Jocoseria es una de esas obras que aúnan, en su concepción editorial, la ficción literaria con la edificación moral que se demandaba por parte de editores y lectores ${ }^{33}$. Así lo ha defendido vehementemente por motivos estrictamente literarios Hannah Bergman ${ }^{34}$ pero si lo consideramos, además, desde una perspectiva comercial, cobraría mucho más sentido el segundo título de la colección cuando se nos presenta como "reprehensión moral y festiva" ${ }^{35}$. Si el componente festivo resulta obvio, a la vista de lo gracioso de los entremeses y de la demanda que tuvieron en los corrales ${ }^{36}$, tampoco cabe descartar-siempre desde el punto de vista editorial- su apariencia de moralidad.

El mercado librario de la época presentaba una grandísima demanda de libros de religión ${ }^{37}$, como señalan los inventarios de la época, en los que se reflejan los libros de horas o devocionarios que contenían la mayoría de las bibliotecas particulares del Siglo de Oro mientras que apenas se registran ediciones de teatro español -ya sea reflejo de una realidad intelectual o de una selección póstuma basada en el valor económico de los libros ${ }^{38}$. Parece lógico, en consecuencia, que el editor del texto de Benavente pretendiese disfrazar el libro de ejemplario a contrario, y no lo presentase tan solo como recreación lega, para -por una parte- ahorrarse las críticas propias del género entremesil pero también con la intención de abrirle a su obra un mayor hueco en el mercado del libro, haciendo que la Jocoseria trascendiese de la concepción de librito de ocios que le sería propia ${ }^{39}$.

piezas que componían el libro (ver I. López Martín, 2012, pp. 8-9). En todo caso, este tipo de prácticas parece incidir en la confusión u ocultación del contenido si atendemos a las palabras de V. Infantes: "[...] lo que no está tan claro es que el lector, y sobre todo el escritor áureo, supiera [...] a qué tipo de obra se estaba refiriendo su interlocutor, si a ésta no se antecedía -o proseguía- algún referente léxico o tipológico que la personalizaba de otros congéneres literarios y no literarios" (2006), p. 17.

${ }^{33}$ Ver K. Whinnom (1980) p. 194.

${ }^{34}$ H. Bergman (1965), pp. 70-75.

${ }^{35}$ Cabe la posibilidad, incluso, de que en algún momento el libro llegase a presentarse ante los censores simplemente bajo el título de Burlas veras o reprehensión moral de los desórdenes públicos, como parece sugerirlo la aprobación de Luis Vélez de Guevara. L. Quiñones de Benavente (2001), pp. 105-106.

${ }^{36}$ Ver L. Quiñones de Benavente (2001), p. 112.

${ }^{37}$ Téngase en cuenta, en este sentido, que las obras de fray Luis de Granada fueron las que más ediciones conocieron (y las que más se vendieron) en nuestro Siglo de Oro (ver K. Whinnom, 1980; E. Rhodes, 1989, y T. J. Dadson, 1998, pp. 51-70).

${ }^{38}$ Ver T. J. Dadson (1998) y J. M. Díez Borque (2010) para la presencia de libros de religión y literarios en las bibliotecas privadas del siglo XVII.

${ }^{39}$ Los editores modernos de la Jocoseria consideran que: "Vargas incide en la carga moral de los entremeses, algo que quizá todo el público no fue capaz de apreciar, pero que sí distinguía las composiciones de Benavente a la vista de otros contemporáneos, como Salas Barbadillo, quien ponderaba, como ya se ha visto, las musas de Benavente, ni "desacatadas 
Este planteamiento se refuerza si atendemos a la labor como editor de Manuel López, responsable de la princeps benaventina. Su nombre se encuentra vinculado a otros libros de teatro (Comedias de Juan Pérez de Montalbán, Alcalá, Antonio Vázquez, 1638, y El mejor de los mejores libros que han salido de comedias nuevas, Madrid, María de Quiñones, 1653) pero también, y principalmente, a varias ediciones de sermones, panegíricos dedicados a santos, libros de historia, ensayos sobre moral y retratos de costumbres (de entre las que destaca el tratadito de Tomás Hurtado dedicado al Chocolate y tabaco, ayuno eclesiástico y natural que imprime, en octavo, Francisco García en el mismo año de la Jocoseria) e incluso las resoluciones morales del R. P. D. Antonini Diana, en latín. Todos los libros que sufraga López, sin embargo, suelen salir de las prensas de tipógrafos dedicados (en mayor o menor medida) a la literatura de ficción, siendo algunos de sus colaboradores más asiduos Diego Díaz de la Carrera, María de Quiñones o el propio Francisco García.

Algo similar se puede decir del mismo García Arroyo. Apenas se puede hablar de su labor previa, pues su nombre empieza a aparecer como responsable en algunas ediciones un par de años antes de que se estampe la colección benaventina, pero teniendo en cuenta su -breve- carrera en conjunto, se constata que su trabajo está muy ligado a la publicación de libros de temática casi exclusivamente religiosa. Su primer impreso aborda ya, desde la perspectiva eminentemente literaria del viaje, la peregrinación religiosa del fraile Juan de Prado. En 1643 ve la luz este Viaje, escrito por Mateo San Francisco (Madrid, Francisco García, 1643), que parece marcar toda su carrera profesional desde un punto de vista temático.

Con estos antecedentes en el editor y el impresor del libro, no debería extrañar que la Jocoseria se imprimiese, pensando en su venta en la librería de Manuel López, como "reprehensión moral y festiva de los desórdenes públicos". Máxime cuando muchos de los libros religiosos más populares venían a componerse también en formato octavo con una presentación que no difería mucho de la que presenta la primera edición de las piezas benaventinas ${ }^{40}$.

Con todo, y por si fuera poco con la consideración moral del librito para hacerse notar dentro del panorama editorial, la Jocoseria contaba todavía con una baza más a su favor. Manuel López tenía cierto gusto como editor por las colecciones de asuntos misceláneos, donde se puede englobar (con todas los matices que se quieran) la recopilación benaventina. El modelo editorial que recurre a la acumulación de piezas con finalidad ejemplarizante se encuentra igualmente, mutatis mutandis,

ni desatacadas". De ahí el título que se pone a la colección Jocoseria. Burlas veras, o reprehensión moral y festiva de los desórdenes públicos, que parece querer subrayar la dimensión de enseñanza y provecho moral en un momento en que el teatro está poco menos que proscrito". I. Arellano, J. M. Escudero y A. Madroñal, en Quiñones de Benavente (2001), p. 47. ${ }^{40}$ Para el rendimiento y la amplia difusión del formato "En octavo", también en el caso de los libros de horas, tratados morales, literatura piadosa y edificante y otras obras de devoción popular, véase V. Infantes (2006), pp. 137-145. 
en los misales y sermonarios que publicó y, sobre todo, en el Enchiridion o manual de los tiempos de fray Alonso Venero (Alcalá, Antonio Vázquez, 1641) y en el $L i$ bro de los secretos de Alejo Piamontés (Alcalá, Antonio Vázquez, 1640 y Alcalá, María Fernández, 1647), que tantas ediciones y versiones conocieron durante el Siglo de $\mathrm{Oro}^{41}$. De nuevo el éxito editorial aparece en los impresos de Manuel López vinculado a unas características populares muy claras: se trata de libritos en octavo (ocasionalmente en dozavo), en torno a (o de menos de) trescientas páginas y compuestos por una colección de casos curiosos ${ }^{42}$.

Al fin, sea por la razón que fuere, lo cierto es que la colección de piezas de Quiñones fue un éxito y sus dos reediciones así lo ratifican ${ }^{43}$. Ambas parten de la impresión de 1645 y ambas copian totalmente la edición de Francisco García. Sin embargo, es muy interesante observar cómo mientras la edición vallisoletana de Juan Antolín de Lago, impresor de oficio de obra bastante irregular ${ }^{44}$, se esmera por conseguir un producto lo más parecido a su original, la que sale de las prensas de Francisco Cays, responsable de apenas unos pocos libros estampados entre 1654 y 1655 , reduce notablemente el tamaño del grado en que se compone el volumen (de Atanasia a Lectura) y simplifica la ornamentación de la primera edición con la intención de crear un auténtico libro de faldriquera, aún más breve y más barato que los anteriores. La situación no es extraordinaria en la época, pues "son muchos los casos en que la aparición de sucesivas ediciones conlleva una reducción del mismo [i.e. el formato], con la correspondiente reducción del cuerpo tipográfico usado y por lo tanto el empleo de menos pliegos de papel por ejemplar, lo que se traduce en un abaratamiento del mismo. Es el mismo proceso que el actual paso de edición normal a libro de bolsillo. Y su finalidad es la misma: ampliar el mercado"45. Aun así, el hecho de que sea la segunda reedición (y no la primera) la que adopta esa reducción material bien podría ser indicio de una popularidad creciente de la colección en Barcelona, adonde llega de la mano de Francisco Cays.

41 Ver M. Fernández Valladares (2007), a propósito del Enchiridion, y M. Rey Bueno (2005) y A. Saguar García (2012), para el Libro de los secretos.

${ }^{42}$ Todas las ediciones del Enchiridion, de El libro de los secretos y de los libros de horas del siglo XVII que hemos localizado se imprimen de manera mayoritaria -si no exclusiva- en octavo o dozavo; es decir, en forma de libro de faldriquera (sea por plegado binario o terciario). Son todos ellos, en consecuencia, libros que, tanto por su formato como por su contenido, no se dirigen a un solo tipo de lector sino que forman parte de los que Jaime Moll consideraba "Libros para todos". J. Moll (2011), pp. 153-166.

${ }^{43}$ A pesar de que las colecciones de entremeses no conocieron una difusión tan boyante como otro tipo de impresos de carácter novelesco, no cabe duda de que tuvieron un público lector interesado en ellas y que su mayor éxito fue (dejando a un lado el particular caso de El viaje entretenido de Agustín de Rojas) el de la Jocoseria, la única colección exclusivamente de teatro breve que conoció tres ediciones diferentes.

${ }^{44}$ J. Delgado Casado (1996), pp. 365-366.

${ }^{45}$ J. Moll (2011) pp. 95-96. 
En este sentido, no parece descabellado pensar que ambas reediciones naciesen a la par, aunque de manera independiente ${ }^{46}$, con la intención de difundir la literatura dramática de Quiñones de Benavente más allá de las fronteras del reino que conoció por primera vez sus piezas reunidas. Si Juan Antolín de Lago comienza su dispar actividad profesional con la Jocoseria (su único impreso literario), no es muy distinto el caso de Francisco Cays, de quien no se conoce más edición de un texto de ficción (entre otros tantos de carácter religioso) que la de nuestra colección de entremeses. A él se debe que las piezas del ingenio toledano circularan por el reino de Cataluña y, por primera vez, sin necesidad de ir encomendadas a ningún dedicatario $^{47}$, probablemente porque la fama del libro era ya aval suficiente para su venta.

A pesar de todo lo dicho hasta aquí a propósito de la Jocoseria, lo cierto es que los textos benaventinos, reunidos o sueltos, dejaron pruebas desde bien pronto en el XVII de su éxito en las prensas españolas. Sus entremeses aderezan hasta finales de siglo las colecciones de teatro -breve- de los principales impresores dedicados al género. Su pluma hace acto de presencia por igual en la Primera parte del Parnaso nuevo y amenidades del gusto (Madrid, Andrés García de la Iglesia, 1670), el Vergel de entremeses (Zaragoza, Diego Dormer, 1675), los Autos sacramentales y al nacimiento de Cristo (Madrid, Antonio Francisco de Zafra, 1675) e incluso en los Verdores del Parnaso (Pamplona, Juan Micón, 1697), en cuyas páginas coincide con los textos de Gil López de Armesto, epígono y admirador suyo.

Por su parte, el modelo editorial que ofrece a los lectores unas cuantas obritas dramáticas de un solo poeta dramático encontró su eco también casi tres décadas más tarde en los Sainetes y entremeses representados y cantados (Madrid, Roque Rico de Miranda, 1674) de Gil López de Armesto ${ }^{48}$, de quien Pedro Francisco Lanini -entremesista también él- asegura: «Don Gil, en tus sainetes no limitas / tu genio al ser humano, pues sagrado / en gracias, en frescura y tablado / a Benavente en ellos resucitas» ${ }^{49}$.

Sin embargo, a pesar de la abundancia de textos que se escribieron, después de la Jocoseria el florido vergel de ediciones se convierte poco a poco en un páramo en donde las recopilaciones de entremeses son apenas un espejismo de lo que fueron, apareciendo cada vez con menos frecuencia y siempre vinculadas a editores o

\footnotetext{
${ }^{46}$ En ambas se observan de manera independiente algunas de las erratas de la primera edición. Los errores separativos de una y otra dejan clara la autonomía de cada una de ellas. Se puede suponer, por tanto, una difusión de la primera Jocoseria por tierras vallisoletanas y barcelonesas, cuando menos. Ver H. Bergman (1965), pp. 265-266.

${ }^{47}$ Mientras la princeps aparecía dirigida a Mario Mastrillo Beltrán, embajador de la archiduquesa de Austria, la edición de Valladolid se ampara en Juan de Rivera Palacio, personalidad destacada en la milicia vallisoletana, a juzgar por las palabras del editor Blas López Calderón impresas en los preliminares.

${ }^{48}$ Ver J. Huerta Calvo (2008).

49 En G. López de Armesto (1674), fol. ๆ6v.
} 
impresores muy concretos del panorama librario del momento. No ha faltado quien achaque la escasa fortuna de estos libritos a su insuficiente capacidad para atraer lectores, pues no es posible "llevar al papel los factores visuales y la maestría cómica de los comediantes barrocos en que estriba buena parte de su éxito escénico",50. Sin embargo, el análisis de la Jocoseria llevado a cabo en estas páginas nos hace plantearnos algunas preguntas más que bien podrían matizar las causas de la caída en desgracia del género editorial en las décadas siguientes del siglo: ¿Acaso el impreso benaventino agotó el filón de las compilaciones de teatro breve? ¿Es posible que sus características editoriales y literarias configurasen un nuevo horizonte de expectativas en los lectores que ninguna otra edición supo satisfacer?

\section{OBRAS CITADAS}

AgUiRRe, José Luis: "Bibliometría elemental sobre la literatura española de los Siglos de Oro", Boletín de la sociedad castellonense de cultura, 63 (1987), pp. 331-341.

ANDRÈS, Christian: "Introducción", en Luis Quiñones de Benavente, Entremeses, Madrid, Cátedra, 1991, pp. 9-64.

ASENSIO, Eugenio: Itinerario del entremés desde Lope de Rueda a Quiñones de Benavente, Madrid, Gredos, 1971.

BARRERA Y LEIRADO, Cayetano Alberto de la: Catálogo bibliográfico y biográfico del teatro antiguo español, desde sus origenes hasta mediados del siglo XVIII, Madrid, Rivadeneyra, 1860.

Bergman, Hannah: Quiñones de Benavente y sus entremeses: con un catálogo biográfico de los actores citados en sus obras, Madrid, Castalia, 1965.

BERGMAN, Hannah: "Los entremeses postcervantinos de la Biblioteca y Museo del Instituto del Teatro de Barcelona”, Estudios escénicos, 14 (1970), pp. 12-17.

BLECUA, José Manuel: "Los entremeses de Quiñones de Benavente”, en Luis Quiñones de Benavente, Entremeses, Madrid, Ebro, 1956, pp. 9-12.

DADSON, Trevor J.: Libros, lectores y lecturas: estudios sobre bibliotecas particulares españolas del Siglo de Oro, Madrid, Arco Libros, 1998.

Delgado CASAdo, Juan: Diccionario de impresores españoles (siglos XV-XVII), Madrid, Arco Libros, 1996.

DíEZ BORQUE, José María: Literatura (novela, poesía, teatro) en bibliotecas particulares del Siglo de Oro español (1600-1650), Madrid-Frankfurt am Main, Universidad de Navarra-Iberoamericana-Vervuert, 2010.

FERNÁNDEZ VALLADARES, Mercedes: "Datos y noticias del pasado y del presente: repertorios y enchiridiones de los tiempos en la imprenta burgalesa del siglo

${ }^{50}$ G. Vega García-Luengos (2010), p. 68. 
XVI (a propósito de la editio princeps recuperada de Alonso de Venero)", en Sagrario López Poza (ed.), Las noticias en los siglos de la imprenta manual, A Coruña, SIELAE-Sociedad de cultura Valle Inclán, 2006, pp. 55-67.

GARCÍA VALDÉS, Celsa Carmen: Ramillete de sainetes, Madrid, EspiralFundamentos, 2012.

GonZÁLEZ MAYA, Juan C.: Entremeses nuevos (1643), Newark (Delaware), Juan de la Cuesta, 2012.

Huerta CAlvo, Javier: El teatro breve en la Edad de Oro, Madrid, Laberinto, 2001.

Huerta Calvo, Javier: "López de Armesto", en Javier Huerta Calvo (dir.), Historia del teatro breve en España, Madrid-Frankfurt am Main, IberoamericanaVervuert, 2008, pp. 444-449.

INFANTES, Víctor: Del libro áureo, Madrid, Calambur, 2006.

LoBATO, María Luisa: "La edición de textos teatrales breves", en Pablo Jauralde, Dolores Noguera y Alfonso Rey (eds.), La edición de textos: actas del I Congreso Internacional de Hispanistas del Siglo de Oro, Londres, Tamesis Books, 1990, pp. 287-294.

LÓPEZ DE ARMESTO, Gil: Sainetes y entremeses representados y cantados, Madrid, Roque Rico de Miranda-Gregorio Rodríguez, 1674.

LÓPEZ MARTín, Ismael: "Las colecciones de entremeses en el Barroco español", Castilla. Estudios de literatura, 3 (2012), pp. 1-17.

MADROÑAL, Abraham: "En torno a la Jocoseria de Luis Quiñones de Benavente", en Francis Cerdan (ed.), Hommage à Robert Jammes, Toulouse, Presses universitaires du Mirail, 1994, pp. 773-786.

Moll, Jaime: "La Tercera parte de las comedias de Lope de Vega Carpio y otros autores, falsificación sevillana", Revista de archivos, bibliotecas y museos, 77 (1974), pp. 619-626.

Moll, Jaime: Problemas bibliográficos del libro del Siglo de Oro, Madrid, Arco Libros, 2011.

NAVARRETE y RIBERA, Francisco de: Flor de sainetes, Antonella Gallo (ed.), Firenze, Alinea, 2001.

Profeti, Maria Grazia: "La Parte primera di Lope", Anuario Lope de Vega, 1 (1995), pp. 137-145.

QUIÑONES DE BENAVENTE, Luis: Entremeses completos I. Jocoseria, Ignacio Arellano, Juan Manuel Escudero y Abraham Madroñal (eds.), Madrid-Frankfurt am Main, Universidad de Navarra-Iberoamericana-Vervuert, 2001.

REY Bueno, Mar: "Primeras ediciones en castellano de los libros secretos de Alejo Piamontés", Pecia complutense, 2 (2005), 26-34.

RHODES, Elizabeth: "El Libro de la oración como el Best-Seller del Siglo de Oro", en Antonio Vilanova (ed.), Actas del X Congreso de la Asociación Internacional de Hispanistas, Barcelona, PPU, 1992, pp. 525-532. 
RoSell, Cayetano: "Advertencia sobre esta edición”, en Colección de piezas dramáticas: entremeses, loas y jácaras escritas por el licenciado Luis Quiñones de Benavente y sacadas de varias publicaciones o de manuscritos recientemente allegados, Librería de los bibliófilos Alfonso Durán, 1872, pp. 1-11.

SAGUAR GARCÍA, Amaranta: "Una edición desconocida del Libro de los secretos de Alejo Piamontés: Juan Perier, Salamanca, 1573", en Guillermo Gómez SánchezFerrer y Amaranta Saguar García (eds.), El pasado ajeno: estudios en honor y recuerdo de Jaime Moll, Córdoba, Academia de cronistas de ciudades de Andalucía, 2012, pp. 59-81.

Vega Carpio, Lope Félix de: Fiestas del Santísimo Sacramento, Zaragoza, Pedro Vergés, 1644.

VEGA GARCÍA-LuENGOS, Germán: "La transmisión del teatro en el siglo XVII", en Javier Huerta Calvo (dir.), Historia del teatro español, Madrid, Gredos, 2003, pp. 1289-1320.

VEGA GARCÍA-LuENGOS, Germán: "Sobre la identidad de las partes de comedias", Criticón, 108 (2010), pp. 57-78.

WhINNOM, Keith: "The problem of the Best-Seller in Spanish Golden Age Literature", Bulletin of Hispanic Studies, 57 (1980), pp. 189-198. 